\title{
Electron spin resonance spectroscopy studies on reduction process of nitroxyl radicals used in molecular imaging
}

\author{
M. Kumara Dhas ${ }^{1}$, A. Jawahar ${ }^{2}$, A. Milton Franklin Benial ${ }^{1, ~ *}$ \\ ${ }^{1}$ Department of Physics, NMSSVN College, Madurai, India \\ ${ }^{2}$ Department of Chemistry, NMSSVN College, Madurai, India
}

\section{Email address:}

nmdhas@gmail.com (M. K. Dhas), ajanthajawahar@yahoo.com (A. Jawahar), miltonfranklin@yahoo.com (A. M. F. Benial)

\section{To cite this article:}

M. Kumara Dhas, A. Jawahar, A. Milton Franklin Benial. Electron Spin Resonance Spectroscopy Studies on Reduction Process of Nitroxyl Radicals used in Molecular Imaging. European Journal of Biophysics. Vol. 2, No. 1, 2014, pp. 1-6.

doi: $10.11648 /$ j.ejb.20140201.11

\begin{abstract}
Electron spin resonance (ESR) spectroscopy studies on the reduction process of nitroxyl radicals were carried out for $1 \mathrm{mM}$ concentration of ${ }^{14} \mathrm{~N}$-labeled nitroxyl radicals in $1 \mathrm{mM}$ concentration of ascorbic acid as a function of time. The half life time and decay rate were estimated for $1 \mathrm{mM}$ concentration of ${ }^{14} \mathrm{~N}$ labeled nitroxyl radicals in $1 \mathrm{mM}$ concentration of ascorbic acid. From the results, the increase in half life time and decrease in decay rate were calculated for TEMPONE compared with TEMPO and TEMPOL radicals, which indicates the higher stability of TEMPONE radical. The observed radical scavenging activity is also higher for TEMPONE radical. The ESR spectrum was also recorded for $1 \mathrm{mM}$ concentration of ${ }^{14} \mathrm{~N}$-labeled nitroxyl radicals in pure water and the ESR parameters, line width, hyperfine coupling constant, g-factor, signal intensity ratio and rotational correlation time were obtained. These results indicate that the TEMPONE radical has narrowest line width and fast tumbling motion compared with TEMPO and TEMPOL. Therefore, this study reveals that the TEMPONE radical can act as a good redox sensitive spin probe for molecular imaging.
\end{abstract}

Keywords: Electron Spin Resonance Spectroscopy, Nitroxyl Radicals, Ascorbic Acid, Half Life Time, Decay Rate

\section{Introduction}

Stable piperidine and pyrrolidine nitroxyl radicals have been widely used in biophysical studies as probes for measuring redox metabolism. It can serve as redox probes providing information regarding cellular redox state, when they are introduced into the sample and the measurement of their spectra can be used to detect the structural changes, motional characteristic of the environment in the sample $[1,2]$. Nitroxyl radicals have also been used as a spin probe for low frequency in vivo electron spin resonance (ESR) experiments to estimate the biological redox status in living experimental animals. The biomedical applications of redox imaging provide the quantification of the nitroxyl radical concentration in tissues, in vivo redox reactions, reactive oxygen species and intracellular antioxidants [3,4].

ESR is a very suitable and versatile method to provide information on the microenvironment of the spin probe, the recorded ESR parameters are dramatically affected by the physical properties such as polarity, viscosity and dynamics of the surrounding space of the probe [5]. The ESR imaging technique can detect free radicals both in vitro and non-invasively in vivo with high sensitivity, which is used to investigate the free radical distribution and metabolism in tissues, organs and the whole body of small animals [6,7]. The ESR X-band frequency $(\sim 9 \mathrm{GHz})$, the magnetic interactions of nitroxide spin labels are extremely sensitive to motion on the nanosecond time scale, which is relevant to the dynamics of bio-molecules [8]. The spin labels, especially nitroxyl radicals exhibit an ESR spectrum which is very sensitive to slight changes in the environment and therefore have been used to characterize the interaction of labeled molecules [9]. In ESR measurements, organ reducing activity was monitored by injecting a stable paramagnetic spin probe into the animals. This spin probe was converted into the corresponding hydroxylamine by one electron reduction and loses its ESR signal in organs. The measurement of ESR signal intensity is equal to the measurement of organ reducing activity against radicals, which is a major factor of organ antioxidative activity. Therefore, the measurement of reducing or oxidizing 
activity by ESR technique using nitroxyl spin probes may provide various information about the reductive or oxidative environments in living tissues, free radical metabolism, in vivo redox status and biological status [10-22].

Reduction of the paramagnetic 3-carbamoyl PROXYL by ascorbic acid to the diamagnetic by hydroxylamine was monitored from a sequence of temporal images, acquired using the three imaging modalities ESR imaging, Overhauser-enhanced magnetic resonance (OMR) imaging, Magnetic resonance (MR) imaging [23]. Utsumi et al. reported that the Dynamic nuclear polarization (DNP) properties of nitroxyl radicals used in Overhauser-enhanced magnetic resonance imaging for simultaneous molecular imaging of redox reactions [24]. Recently, the stable nitroxyl radicals have been used as redox sensitive probe for in vivo ESR and OMR imaging techniques [25-31]. This proposed work determines the half life time and the signal decay rate for the piperidine nitroxyl radicals. Moreover, in order to understand the reduction process and find the suitable nitroxyl spin probe among the piperidine nitroxyl radicals for in vivo/in vitro ESR and OMR imaging techniques. Here, we report the ESR spectroscopy studies on the reduction process of $1 \mathrm{mM}$ concentration of ${ }^{14} \mathrm{~N}$-labeled TEMPONE, TEMPO and TEMPOL in $1 \mathrm{mM}$ concentration of ascorbic acid.

\section{Materials and Methods}

\subsection{Chemicals}

The spin probes, 4-oxo-2,2,6,6- tetramethyl -piperidine -1-oxyl (TEMPONE), 2,2,6,6-tetramethyl piperidine -1-oxyl (TEMPO), 4-hydroxy -2,2,6,6-tetramethylpiperidine-1-oxy (TEMPOL) and ascorbic acid were purchased from Sigma Aldrich Chemical Co, St. Louis, MO, USA.

\subsection{ESR Measurements}

ESR spectra were recorded for $1 \mathrm{mM}$ concentration of ${ }^{14} \mathrm{~N}$ labeled TEMPONE, TEMPO and TEMPOL in $1 \mathrm{mM}$ concentration of ascorbic acid as a function of time using a Bruker EMS plus X-band ESR spectrometer by varying the magnetic field, 342-352 $\mathrm{mT}$; with modulation frequency, $100 \mathrm{kHz}$; field modulation amplitude, $0.2 \mathrm{mT}$; conversion time, $10 \mathrm{~ms}$; radio-frequency power, $2 \mathrm{~mW}$; receiver gain, 1000; sweep width, $10 \mathrm{mT}$; sweep time, $10 \mathrm{~s}$; point field resolution, 1024; and microwave frequency, 9.86 GHz. The ESR spectra were recorded in the first derivative mode at $27^{\circ} \mathrm{C}$. The temperature was controlled using a controller with water as a coolant. The ESR spectrum was also recorded for $1 \mathrm{mM}$ concentration of ${ }^{14} \mathrm{~N}$ labeled nitroxyl radicals in pure water with an accuracy of $\sim \pm 0.5 \mu \mathrm{T}$.

\section{Results and Discussion}

The ring structure and abbreviations of ${ }^{14} \mathrm{~N}$-labeled TEMPONE, TEMPO and TEMPOL are given in Table 1. The ESR parameters, such as the line width, g-factor, hyperfine coupling constant and rotational correlation time for $1 \mathrm{mM}$ concentration of ${ }^{14} \mathrm{~N}$-labeled TEMPONE, TEMPO and TEMPOL in pure water are listed in Table 2. The paramagnetic nitroxyl radical was converted into the paramagnetic hydroxylamine form in the reaction with ascorbic acid, which leads to the reduction of ESR signal intensity. Fig 1 shows the schematic diagram of the reduction process of nitroxyl radical. The ESR spectra of 1 $\mathrm{mM}$ concentration of ${ }^{14} \mathrm{~N}$-labeled TEMPONE, TEMPO and TEMPOL in pure water and $1 \mathrm{mM}$ concentration of ascorbic acid as a function of time $(\mathrm{t})$ are shown in Figs 2-4.

Table 1. The ring structure and abbreviations of nitroxyl radicals.

\begin{tabular}{lll}
\hline Ring structure & Substituents (R) & Abbreviations \\
\hline & $=\mathrm{O}$ & TEMPONE \\
\hline
\end{tabular}

Table 2. ESR parameters of $1 \mathrm{mM}{ }^{14} \mathrm{~N}$ labeled TEMPONE, TEMPO and TEMPOL in pure water.

\begin{tabular}{llllll}
\hline Sample & $\begin{array}{l}\text { Line } \\
\text { width } \\
\boldsymbol{\Delta} \mathbf{B} \\
(\boldsymbol{\mu} \mathbf{T})\end{array}$ & $\begin{array}{l}\text { Hyperfine } \\
\text { coupling } \\
\text { constant } \\
(\mathbf{m} \mathbf{T})\end{array}$ & g-factor & $\begin{array}{l}\text { Signal } \\
\text { intensity } \\
\text { ratio } \\
\left(\mathbf{h}_{\mathbf{0}} / \mathbf{h}_{-1}\right)\end{array}$ & $\begin{array}{l}\text { Rotational } \\
\text { correlation } \\
\text { time } \tau_{\mathbf{R}}(\mathbf{s}) \\
\left(\times \mathbf{1 0}^{-11}\right)\end{array}$ \\
\hline TEMPONE & 136 & 1.725 & 2.0068 & 1.041 & 1.817 \\
TEMPO & 151 & 1.593 & 2.0070 & 1.044 & 2.167 \\
TEMPOL & 185 & 1.686 & 2.0078 & 1.075 & 4.444 \\
\hline
\end{tabular}

\subsection{Line Width}

The observed line width values are given in Table 2 . The line width broadening is due to the dipolar and spin exchange interactions of agent concentrations. These results agree well with the previous studies [32-35]. The TEMPONE has a narrow line width compared with TEMPO and TEMPOL radicals. The obtained line width values were $\sim 11$ and $36 \%$ higher for TEMPO and TEMPOL compared with TEMPONE radical. The narrowest line width of TEMPONE radical indicates that the interaction between the carbonyl group of TEMPONE and water proton is less, but the interaction between the $\mathrm{OH}$ group of TEMPOL and water proton is more [36]. The line width value of TEMPO shows only $11 \%$ increase, which is due to the interaction between the substituent (R), hydrogen atom of TEMPO and water proton. 


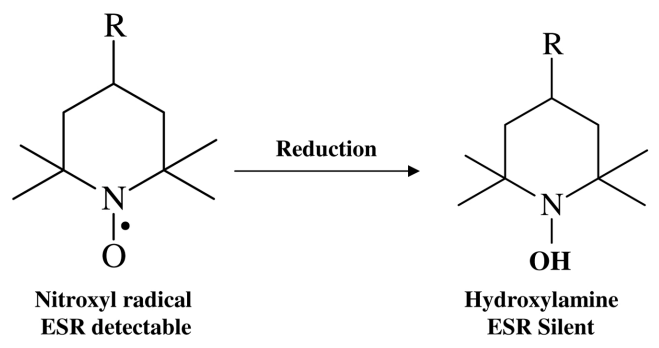

Figure 1. Schematic diagram of reduction process of nitroxyl radical, $R$ represents substituents.

\subsection{Hyperfine Coupling Constant and g-factor}

Table 2 shows the hyperfine coupling constant and g-factor for $1 \mathrm{mM}$ concentration of ${ }^{14} \mathrm{~N}$-labeled TEMPONE, TEMPO and TEMPOL radicals. The hyperfine coupling constants for the nitroxyl radicals agree well with the previous study [33,36]. The obtained hyperfine coupling constant values indicate that the Fermi contact interaction is less for TEMPO compared with TEMPONE and TEMPOL. The g-factor value indicates that the isotropic nature of the system.

\subsection{Signal Intensity Ratio}

The signal intensity ratio was calculated from the height of the central line and high field line of the ESR spectrum. The signal intensity ratio values of $1 \mathrm{mM}$ concentration of ${ }^{14} \mathrm{~N}$-labeled TEMPONE, TEMPO and TEMPOL in pure water are listed in Table 2. The ESR signal intensity ratio value becomes unity for all nitroxyl radicals in pure water, which reveals that the homogenous nature of the samples. These results agree well with the reported values [36].

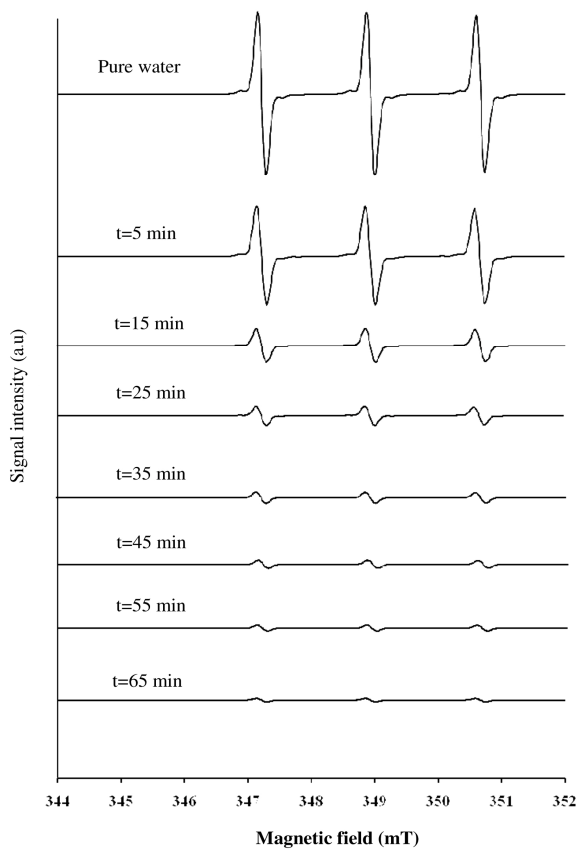

Figure 2. ESR spectra of $1 \mathrm{mM}$ concentration of ${ }^{14} \mathrm{~N}$-labeled TEMPONE in pure water and $1 \mathrm{mM}$ concentration of ascorbic acid as a function of time (t).

\subsection{Rotational Correlation Time}

Conventional ESR spectroscopy can detect changes in the rotational correlation time $\left(\tau_{\mathrm{R}}\right)$ of spin probes ranging from $10^{-12}$ to $10^{-9} \mathrm{~s}$, which corresponds to the lifetime of the probe in a given orientation. In this motional range, the ESR spectrum of nitroxyl radical consists of three lines, and $\tau_{\mathrm{R}}$ can be calculated according to the method of Knowles et al. [36,37].

$$
\tau_{R}=6.5 \times 10^{-10} \Delta B_{0}\left[\left(h_{0} / h_{-1}\right)^{1 / 2}-1\right]
$$

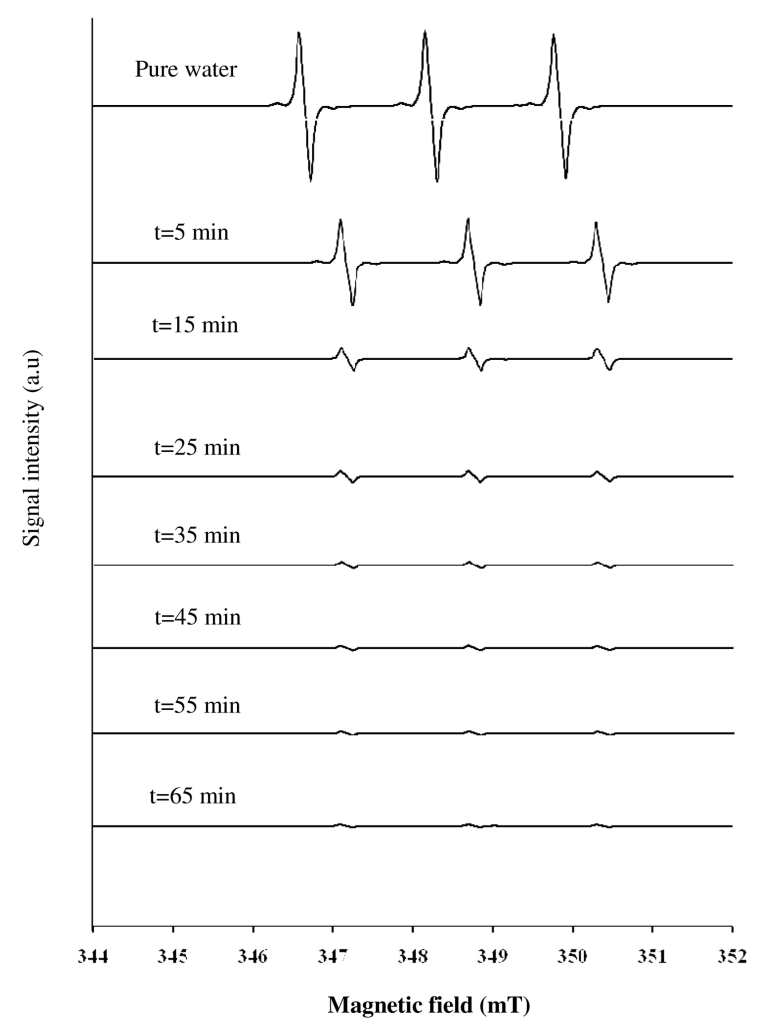

Figure 3. ESR spectra of $1 \mathrm{mM}$ concentration of ${ }^{14} \mathrm{~N}$-labeled TEMPO in pure water and $1 \mathrm{mM}$ concentration of ascorbic acid as a function of time (t).

Where, $h_{0}$ and $h_{-1}$ are the heights of the central and high field line in the ESR spectrum, respectively, and $\Delta \mathrm{B}_{0}$ is the line width of the central line in Gauss. The rotational motion of the spin probe was assumed to be isotropic.

The rotational correlation time for $1 \mathrm{mM}$ concentration of ${ }^{14} \mathrm{~N}$-labeled TEMPONE, TEMPO and TEMPOL in pure water is shown in Table 2. The rotational correlation time agrees well with the previous study [36]. The decrease in rotational correlation time was observed for TEMPONE compared with TEMPO and TEMPOL in pure water. These results show that the TEMPONE radical has fast tumbling motion compared with TEMPO and TEMPOL radical. The fast tumbling motion confirms the less interaction between the carbonyl group of TEMPONE radical and water protons. The narrowest line width also indicates the fast tumbling motion of the TEMPONE radical. 


\subsection{Reduction Process and Stability}

Nitroxyl radicals react with reductants and their reduction process depend on the basic structure, chemical and physical properties of the nitroxyl radicals. Figs 2-4 show the ESR spectrum of $1 \mathrm{mM}$ concentration of ${ }^{14} \mathrm{~N}$-labeled TEMPONE, TEMPO and TEMPOL in $1 \mathrm{mM}$ concentration of ascorbic acid as a function of time, which demonstrate the reduction process of nitroxyl radicals towards the ascorbic acid. During the reduction process, the nitroxyl radical was converted into hydroxylamine and loses its paramagnetic nature, which leads to the ESR signal decay.

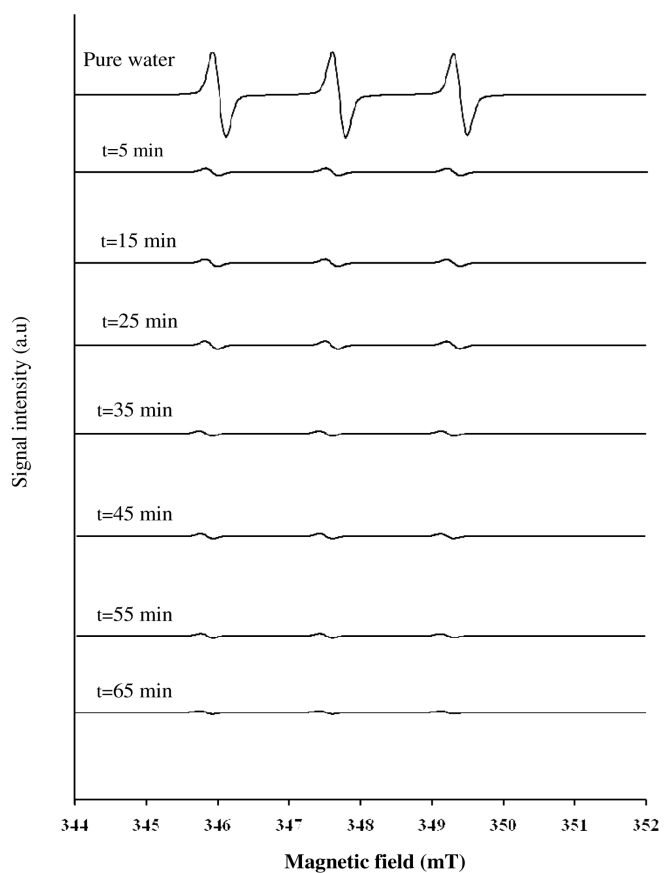

Figure 4. ESR spectra of $1 \mathrm{mM}$ concentration of ${ }^{14} \mathrm{~N}$-labeled TEMPOL in pure water and $1 \mathrm{mM}$ concentration of ascorbic acid as a function of time $(t)$

\subsection{Half Life Time and the Decay Rate}

The ESR signal intensity values were fitted with a simple model of an exponential decay equation and an added constant offset, which is used to determine the half life time $\left(t_{1 / 2}\right)$ and the decay rate $(1 / \tau)$ of the nitroxyl radical in ascorbic acid $[10,40]$. The ESR spectral intensity I ( $t)$ can be expressed as

$$
I(t)=I_{0} e^{-t / \tau}+N
$$

where, $I_{0}$ is the initial value of ESR signal intensity, $t$ is the time and $1 / \tau$ is the decay rate.

Fig 5a shows the fitted exponential decay curve for $1 \mathrm{mM}$ concentration of ${ }^{14} \mathrm{~N}$-labeled TEMPONE, TEMPO and TEMPOL in $1 \mathrm{mM}$ concentration of ascorbic acid at various time intervals. The curve fitting shows the best correlation $\left(\mathrm{R}^{2}>0.99\right)$. The half life time of $1 \mathrm{mM}$ concentration of ${ }^{14} \mathrm{~N}$-labeled TEMPONE, TEMPO and
TEMPOL in $1 \mathrm{mM}$ concentration of ascorbic acid as a function of time was calculated by the equation

$$
t_{1 / 2}=\tau \ln (2)
$$

The half life time and decay rate values for TEMPONE, TEMPO and TEMPOL are listed in Table 3. The values given are the averages of three repeated experiments. The increase in half life time and decrease in decay rate were obtained for TEMPONE compared with TEMPO and TEMPOL radical, which indicates the higher stability of TEMPONE radical.
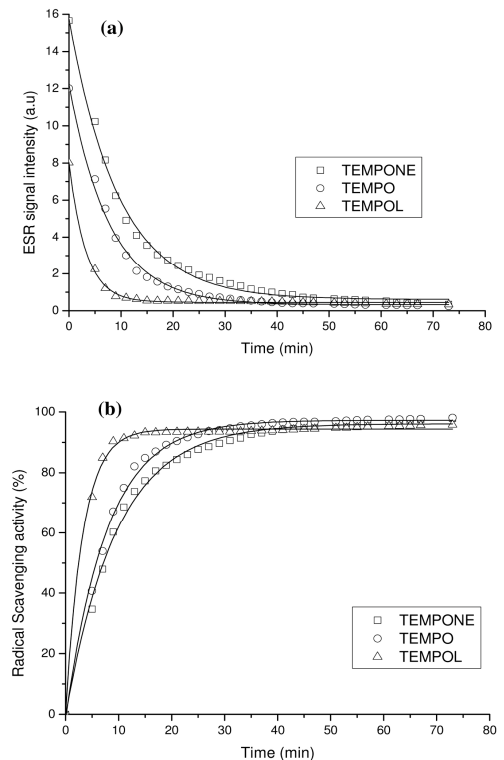

Figure 5a. The exponential decay curve fit for the ESR signal intensity and $\boldsymbol{b}$ the radical scavenging activity of $1 \mathrm{mM}$ concentration of ${ }^{14} \mathrm{~N}$-labeled TEMPONE, TEMPO, TEMPOL in pure water and $1 \mathrm{mM}$ concentration of ascorbic acid at various time intervals.

Table 3. The half life time and decay rate of $1 \mathrm{mM}{ }^{14} \mathrm{~N}$ labeled TEMPONE, TEMPO and TEMPOL in $1 \mathrm{mM}$ concentration of ascorbic acid.

\begin{tabular}{lcc}
\hline Sample & Half life time $\mathbf{t}_{\mathbf{1} / \mathbf{2}}(\mathbf{m i n})$ & $\begin{array}{c}\text { Signal decay rate } \mathbf{1} / \boldsymbol{\tau} \\
\left(\mathbf{m i n}^{-1}\right)\end{array}$ \\
\hline TEMPONE & 6.662 & 0.104 \\
TEMPO & 5.412 & 0.128 \\
TEMPOL & 2.263 & 0.306 \\
\hline
\end{tabular}

\subsection{Radical Scavenging Activity}

The Radical scavenging activity (RSA) was expressed as the inhibition percentage of nitroxyl radical by the sample and was calculated using the formula $[38,39]$

$$
R S A(\%)=\frac{\left(I_{0}-I_{t}\right)}{I_{0}} \times 100
$$

where $\mathrm{I}_{0}$ is the signal intensity of central line from the ESR spectrum, when nitroxyl radicals in pure water, $I_{t}$ is the signal intensity of central line from the ESR spectrum, when nitroxyl radicals in ascorbic acid at time t. Fig. $5 b$ 
shows the radical scavenging activity (\%) of $1 \mathrm{mM}$ concentration of ${ }^{14} \mathrm{~N}$-labeled TEMPONE, TEMPO and TEMPOL in $1 \mathrm{mM}$ concentration of ascorbic acid at various time intervals. The observed radical scavenging activity is higher for TEMPONE radical compared with TEMPO and TEMPOL radicals.

\section{Conclusions}

The ESR parameters such as the line width, g-factor, hyperfine coupling constant and rotational correlation time for $1 \mathrm{mM}$ concentration of ${ }^{14} \mathrm{~N}$-labeled TEMPONE, TEMPO and TEMPOL in pure water were obtained. From the results, the TEMPONE radical has narrowest line width and fast tumbling motion compared with TEMPO and TEMPOL radicals. The reduction process was recorded for $1 \mathrm{mM}$ concentration of ${ }^{14} \mathrm{~N}$-labeled TEMPONE, TEMPO and TEMPOL in $1 \mathrm{mM}$ concentration of ascorbic acid as a function of time using X-band ESR spectrometer. The half life time and decay rate were estimated for $1 \mathrm{mM}$ concentration of ${ }^{14} \mathrm{~N}$ labeled nitroxyl radicals in $1 \mathrm{mM}$ concentration of ascorbic acid. From the results, the increase in half life time and decrease in decay rate were calculated for TEMPONE compared with TEMPO and TEMPOL radicals, which indicates the higher stability of TEMPONE radical. The observed radical scavenging activity is also higher for TEMPONE radical. Hence, the TEMPONE radical can act as a good redox sensitive spin probe for in vivo/in vitro ESR and OMR Imaging.

\section{Acknowledgements}

The authors thank the management of NMSSVN College for encouragement and permission to carry out this research. This work was supported by the UGC Research Award scheme, New Delhi (F.No.30-35/2011(SA-II)).

\section{References}

[1] B. Gallez, G. Bacic, F. Goda, J. Jiang, J.A. O'Hara, J.F. Dunn and H.M. Swartz, "Use of nitroxides for assessing perfusion, oxygenation, and viability of tissues: In vivo EPR and MRI studies", Magn. Reson. Med. vol. 35, no. 1, pp. 97-106, 1996.

[2] R. Franco, O.J. Schoneveld, A. Pappa and M. I. Panayiotidis, "The central role of glutathione in the pathophysiology of human diseases", Arch Physiol Biochem. vol. 113, pp. 234-258, 2007

[3] R.M. Davis, J. B. Mitchell and M.C. Krishna, "Nitroxides as cancer imaging agents", Anticancer agents Med Chem. vol. 11, no. 4, pp. 347-358, 2011.

[4] R.M. Davis, A.L. Sowers, W. Degraff, M. Bernardo, A. Thetford, M.C Krishna and J.B Mitchell, "A novel nitroxide is an effective brain redox imaging contrast agent and in vivo radioprotector", Free Radic. Biol. Med. vol. 51, no. 3, pp. 780-790, 2011.
[5] L. J Berliner, V. Khramtsov, H. Fujii and T.L. Clanton, "Unique in vivo applications of spin traps". Free Radic. Biol. Med. vol. 30, no. 5, pp. 489-499, 2001.

[6] S. Fujii, Y. Suzuki, T. Toshimura and H. Kamada, "In vivo three dimensional EPR imaging of nitric oxide production from isosorbide dinitrate in mice", Am J Physiol sastrointest Liver Physiol. vol. 274, pp. G857-G862, 1998.

[7] G. He, S. Petrvakov, P. Kuppusamy, A. Samouilov and J. L. Zweier, "EPR imaging: A technique enabling in vivo mapping of free radicals and redox metabolism in biomedical applications", Analytical Sciences vol. 17, pp. i507-i510, 2001.

[8] G. L. Millhauser, "Selective placement of electron spin resonance spin labels: new structural methods for peptides and proteins", Trends in Biochemical Sciences vol. 17, no. 11, pp. 448-452, 1992.

[9] E.M.K. Hedin, K. Hult, O. G. Mouritsen and P. Hoyrup, "Low microwave amplitude ESR spectroscopy: Measuring spin-relaxation interactions of moderately immobilized spin labels in proteins", Journal of Biochemical and Biophysical Methods, vol. 60, no. 2, pp. 117-138, 2004.

[10] G. L. Caia, O.V. Efimova, M. Velayutham, M. A. El-Mahdy, T. M. Abdelghany, E. Kesselring, S. Petryakov, Z. Sun, A. Samouilov and J. L. Zweier, "Organ specific mapping of in vivo redox state in control and cigarette smoke-exposed mice using ESR/NMR co-imaging", J. Magn.Reson. vol.216, pp.21-27, 2012.

[11] A. Hirayama, K. Yoh, S. Nagase, A. Udeda, K. Itoh, N. Morito, K. Hirayama, S. Takahashi, M. Yamamoto and A. Koyama, "EPR imaging of reducing activity in Nrf2 transcriptional factor-deficient mice", Free Radic. Biol. Med vol. 34, no. 10, pp. 1236-1242, 2003.

[12] Y. Miura and T. Ozawa, "Non invasive study of radiation-induced oxidative damage using in vivo electron spin resonance" Free Radic. Biol. Med. vol. 28, no. 6, pp. 854-859, 2000.

[13] H. Togashi, T. Matsuo, H. Shinzawa, Y. Takeda, L. Shao, K. Oikawa, H. Kamada and T. Takahashi, "Ex vivo measurement of tissue distribution of a nitroxide radical after intravenous injection and its in vivo imaging using a rapid scan ESR-CT system", Magn. Reson. Imaging vol. 18, no. 2, pp. 151-156, 2000.

[14] A. Hirayama, S. Nagase, A. Ueda, T. Oteki, K. Takada, M. Obara, M. Inoue, K. Yoh, K. Hirayama and A. Koyama, "In vivo imaging of oxidative stress in ischemia-reperfusion renal injury using electron paramagnetic resonance", Am. J. Physiol. Renal. Physiol. vol. 288, no. 3, pp. F597-F603, 2005.

[15] H. Sano, M. Naruse, K. Matsuoto, T. Oi and H. Utsumi, "A new nitroxyl-probe with high retention in the brain and its application for brain imaging". Free Radic. Biol. Med. vol. 28 , no. 6, pp. 959-956, 2000.

[16] K. Kasazaki, K. Yasukawa, H. Sano and H. Utsumi, "Non-invasive analysis of reactive oxygen species generated in $\mathrm{NH}^{4} \mathrm{OH}$ induced gastric lesions of rats using a $300 \mathrm{MHz}$ in vivo ESR technique". Free radic. Res. vol. 37, no. 7, pp.757-766, 2003.

[17] J. Han, K.Takeshita and H. Utsumi, "Noninvasive detection of hydroxyl radical generation in lung by diesel exhaust 
particles”, Free Radic. Biol. Med. Vol. 30, no. 5, pp. 516-525, 2001.

[18] N. Phumala, T. Ide and H. Utsumi, "Noninvasive evalution of in vivo free radicals reactions catalyzed by iron using in vivo ESR spectroscopy", Free Radic. Biol. Med. vol. 26, no. 9-10, pp. 1209-1217, 1999.

[19] H. M. Swartz, Principles of the metabolism of Nitroxides and their implications for spin trapping. Free Radic. Res. Commun. vol. 9, no. 3-6, pp. 399-405, 1990.

[20] J. Brnjas-Krajevi, M. Kveder, G. Pifat, S. Pecar and M. Schara, "The ESR kinetic study of lipid phase in HDL", Croatica Chemica Acta, vol. 74, no. 1, pp. 147-160, 2001.

[21] M. Elas, B.B. Williams, A. Parasca, C. Mailer, C.A. Pelizzari, M.A. Lewis, J.N. River, G. S. Karczmar, E. D. Barth and H. J. Halpern, "Quantitative tumor oxymetric images from $4 \mathrm{~d}$ electron paramagnetic resonance imaging (EPRI): methodology and comparison with blood oxygen level-dependent (bold) MRI”, Magn. Reson. Med. Vol. 49, no. 4, pp. 682-691, 2003.

[22] K. Matsumoto, S. Subramanian, N. Devasahayam, T. Aravalluvan, R. Murugesan, J.A Cook, J. B. Mitchell and M.C Krishna, "Electron paramagnetic resonance imaging of tumor hypoxia: Enhanced spatial and temporal resolution for in vivo $\mathrm{pO}_{2}$ determination", Magn. Reson. Med. Vol. 55, no. 5, pp. 1157-1163, 2006.

[23] F. Hyodo, R. Murugesan, K. Matsumoto, E. Hyodo, S. Subramanian, J. B. Mitchell and M.C Krishna, "Monitoring redox-sensitive paramagnetic contrast agent by EPRI, OMRI, MRI”, J. Magn.Reson. vol. 190, no. 1, pp. 105-112, 2008 .

[24] H. Utsumi, K. Yamada, K. Ichikawa, K. Sakai, Y. Kinoshita, S. Matsumoto and M. Nagai, "Simultaneous molecular imaging of redox reactions monitored by Overhauser-enhanced MRI with ${ }^{14} \mathrm{~N}$ and ${ }^{15} \mathrm{~N}$-labeled nitroxyl radicals", Proc. Natl. Acad. Sci. USA vol.103, no. 5, pp. 1463-1468, 2006.

[25] K. Takeshita, K. Saito, J. Ueda, K. Anzai and T. Ozawa, "Kinetic study on ESR signal decay of nitroxyl radicals, potent redox probes for in vivo spectroscopy, caused by reactive oxygen species", Biochimica et Biophysica Acta vol. 1573, no. 2, pp. 156-164, 2002.

[26] A. Ueda, S. Nagase, H. Yokoyama, M. Tada, H. Noda, H. Ohya, H. Kamada, A. Hirayama and A. Koyama, "Importance of renel mitochondria in the reduction of TEMPOL, a nitroxyl radical”, Molecular and cellular Biochemistry vol. 244, no. 1-2, pp. 119-124, 2003.

[27] Y. Kinoshita, K. Yamada, T. Yamasaki, F. Mito, M. Yamato, N. Kosem, H. Deguchi, C. Shirahama, Y. Ito, K. Kitagawa, N. Okukado, K. Sakai and H. Utsumi, In vivo evaluation of novel nitroxyl radicals with reduction stability. Free Radic. Biol. Med. vol. 49, no. 11, pp. 1703-1709, 2010.

[28] M.C. Krishna, S. English, K. Yamada, J. Yoo, R. Murugesan, N. Devasahayam, J.A. Cook, K. Golman, J. H. Ardenkjaer-Larsen, S. Subramanian and J. B. Mitchell, "Overhauser enhanced magnetic resonance imaging for tumor oximetry: Coregistration of tumor anatomy and tissue oxygen concentration", Proc. Natl. Acad. Sci. USA vol. 99, no. 4, pp. 2216-2221, 2002.

[29] H. G. Fujii, H. Sato-Akaba, M.C Emoto, K. Itoh, Y. Ishihara and H. Hirata, "Noninvasive mapping of the redox status in septic mouse by in vivo electron paramagnetic resonance imaging", Magn. Reson. Imaging vol. 31, no. 1, pp. 130-138, 2013.

[30] N. Nestle, K. Shet and D. J. Lurie, "Proton electron double resonance imaging of free radical distribution in environmental science applications-first results and perspectives", Magn. Reson. Imaging vol. 23, no. 2, pp. 183-189, 2005.

[31] A.M.F. Benial, H. Utsumi, K. Ichikawa, R. Murugesan, K. Yamada, Y. Kinoshita, T. Naganuma and M. Kato, "Dynamic nuclear polarisation studies of redox sensitive nitroxyl spin probes in liposomal solution" J. Magn. Reson. vol. 204, no. 1, pp. 131-138, 2010.

[32] A.M.F. Benial, K. Ichikawa, R. Murugesan, K. Yamada and H. Utsumi, "Dynamic nuclear polarization properties of nitroxyl radicals used in overhauser-enhanced MRI for simultaneous molecular imaging”, J. Magn. Reson. vol. 273, no. 2, pp.273-282, 2006.

[33] I. Nicholson, D. J. Lurie and F. J. L. Robb, "The applications of proton electron double resonance imaging technique to proton mobility studies" J. Magn. Reson. Ser. B 1994, 104, 250-255.

[34] P.L De Sousa, R.E. De Souza, M. Engelsberg and L.A. Colnago, "Mobility and free radical concentration effects in proton electron double resonance imaging" J. Magn. Reson. vol. 135 , no. 3, pp. 118-15, 1998.

[35] D. Grucker, T. Gilberteau, B. Eclancher, J. Chambron, R. Chiarelli, A. Rassat, G. Subra and B. Gallez, "Dynamic nuclear polarisation with nitroxides dissolved in biological fluids”, J. Magn. Reson. vol. 106, no. 2, pp. 101-109, 1995.

[36] A.M.F. Benial, M. K. Dhas and A. Jawahar, "Rotational correlation time studies on nitroxyl radicals usin $300 \mathrm{MHz}$ ESR spectrometer in high viscous liquid" Appl. Magn. Reson. vol. 40, no. 3, pp. 311-319, 2011

[37] P.F. Knowles, D. Marsh, H. W. E. Rattle, Magnetic Resonance of Biomolecules: An Introduction to the Theory and Practice of NMR and ESR in Biological Systems. (John Wiley and Sons, London, UK, 1976).

[38] R. Amarowicz, R.B. Pegg, P. Rahimi-Moghaddam, B. Barl and J.A. Weil, "Free-radical scavenging capacity and antioxidant activity of selected plant species from the Canadian prairies", Food Chemistry vol. 84, no. 4, pp. 551-562, 2004.

[39] S. Mathew and T. E. Abraham, "In vitro antioxidant activity and scavenging effects of cinnamomum verum leaf extract assayed by different methodologies" Food Chem. Toxicol. vol. 44, no. 2, pp. 198-206, 2006.

[40] R. M. Davis, S. Matsumoto, M. Bernardo, A. Sowers, K. Matsumoto, M. C. Krishna and J.B. Mitchell, "Magnetic resonance imaging of organic contrast agents in mice: capturing the whole-body redox landscape", Free Radic. Biol. Med. vol. 50, no. 3, pp. 459-468, 2011. 